\title{
Experimental moose reduction lowers wolf density and stops decline of endangered caribou
}

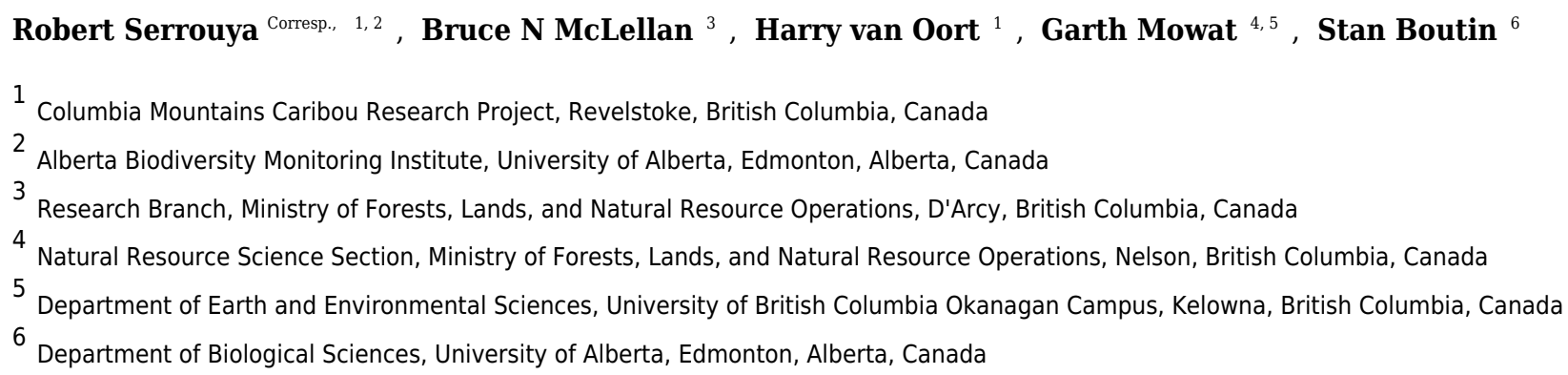

The expansion of moose into southern British Columbia caused the decline and extirpation of woodland caribou due to their shared predators, a process commonly referred to as apparent competition. Using an adaptive management experiment, we tested the hypothesis that reducing moose to historic levels would reduce apparent competition and therefor recover caribou populations. Nested within this broad hypothesis were three specific hypotheses: 1) sport hunting could be used to substantially reduce moose numbers to an ecological target; 2 ) wolves in this ecosystem were primarily limited by moose abundance; and 3) caribou were limited by wolf predation. These hypotheses were evaluated with a before-after control-impact $(\mathrm{BACl})$ design that included response metrics such as population trends and vital rates of caribou, moose, and wolves. Three caribou subpopulations were subject to the moose reduction treatment and two were in a reference area where moose were not reduced. When the moose harvest was increased, the moose population declined substantially in the treatment area (by 70\%) but not the reference area, suggesting that the policy had the desired effect and was not caused by a broader climatic process. Wolf numbers subsequently declined in the treatment area, with wolf dispersal rates $2.5 \times$ greater, meaning that dispersal was the likely mechanism behind the wolf numerical response, though reduced recruitment and starvation was also documented in the treatment area. Caribou adult survival increased from 0.78 to 0.88 in the treatment area, but declined in the reference. Caribou recruitment was unaffected by the treatment. The largest caribou subpopulation stabilized in the treatment area, but declined in the reference area. The observed population stability is comparable to other studies that used intensive wolf control, but is insufficient to achieve recovery, suggesting that multiple limiting factors and corresponding management tools must be addressed 
simultaneously to achieve population growth. 
1 EXPERIMENTAL MOOSE REDUCTION LOWERS WOLF DENSITY AND STOPS DECLINE OF ENDANGERED

2

3

4

\section{CARIBOU}

ROBERT SERROUYA ${ }^{1}$, Alberta Biodiversity Monitoring Institute, University of Alberta, Edmonton, Alberta, Canada; Columbia Mountains Caribou Research Project, Revelstoke, British Columbia, Canada

BRUCE N. MCLELLAN, Research Branch, British Columbia Ministry of Forests, Lands, and Natural Resource Operations, D'Arcy, British Columbia, Canada

HARRY VAN OORT, Columbia Mountains Caribou Research Project, Revelstoke, British Columbia, Canada

GARTH MOWAT, Natural Resource Science Section, British Columbia Ministry of Forests, Lands, and Natural Resource Operations, Nelson, British Columbia, Canada; Department of Earth and Environmental Sciences, University of British Columbia Okanagan Campus, Kelowna, British Columbia, Canada

STAN BOUTIN, Department of Biological Sciences, University of Alberta, Edmonton, Alberta, Canada

${ }^{1}$ Corresponding author; email: serrouya@ualberta.ca 


\section{Abstract}

21 The expansion of moose into southern British Columbia caused the decline and extirpation of 22 woodland caribou due to their shared predators, a process commonly referred to as apparent 23 competition. Using an adaptive management experiment, we tested the hypothesis that 24 reducing moose to historic levels would reduce apparent competition and therefor recover 25 caribou populations. Nested within this broad hypothesis were three specific hypotheses: 1) 26 sport hunting could be used to substantially reduce moose numbers to an ecological target; 2) 27 wolves in this ecosystem were primarily limited by moose abundance; and 3) caribou were 28 limited by wolf predation. These hypotheses were evaluated with a before-after control-impact 29 (BACl) design that included response metrics such as population trends and vital rates of 30 caribou, moose, and wolves. Three caribou subpopulations were subject to the moose 31 reduction treatment and two were in a reference area where moose were not reduced. When the moose harvest was increased, the moose population declined substantially in the treatment area (by 70\%) but not the reference area, suggesting that the policy had the desired effect and was not caused by a broader climatic process. Wolf numbers subsequently declined in the treatment area, with wolf dispersal rates $2.5 \times$ greater, meaning that dispersal was the likely mechanism behind the wolf numerical response, though reduced recruitment and starvation was also documented in the treatment area. Caribou adult survival increased from 0.78 to 0.88 in the treatment area, but declined in the reference. Caribou recruitment was unaffected by the treatment. The largest caribou subpopulation stabilized in the treatment area, but declined in the reference area. The observed population stability is comparable to other studies that used intensive wolf control, but is insufficient to achieve recovery, suggesting that multiple limiting factors and corresponding management tools must be addressed simultaneously to 43 achieve population growth.

\section{Introduction}

When species colonize new areas, the consequences for native organisms can be 47 profound, often with negative impacts caused by competition or predation. An exotic predator 48 can have dramatic effects on native prey (Smith and Quin 1996), particularly on islands where 
49 prey have evolved few anti-predator strategies (Sinclair et al. 1998). Similarly, extreme forms of 50 interference competition can have pronounced and obvious impacts, such as the invasion of

51 the Eurasian zebra mussel (Dreissena polymorpha) into North America where it now dominates 52 available substrate and smothers native bivalves (Ricciardi et al. 1998). In both cases, the 53 ecological interactions can be severe but straightforward to document. Interactions involving 54 indirect processes can be more difficult to confirm because they are not well explained simply 55 by tracking the abundance of individuals. One such process is apparent competition (Holt 56 1977), which can occur when a novel prey species colonizes a new area, stimulating an increase

57 in the abundance of one or more predator species. The novel prey need not be an introduced 58 exotic, but may be expanding its range either because of natural or anthropogenic factors 59 (Dawe et al. 2014). A secondary, but native prey may then become victim of apparent 60 competition, usually because it is less fecund or less able to escape predation than the novel prey. The secondary prey can be driven to extinction because there is little or no feedback between secondary prey abundance and predator numbers, given that predators are sustained by the more abundant novel prey (Holt 1977, Latham et al. 2011). Identifying this mechanism can be difficult because the cause of the secondary prey's decline could be confused with other indirect interactions such as exploitative competition.

Woodland caribou (Rangifer tarandus caribou) represent a classic case of apparent competition, especially the endangered ecotype of mountain caribou that inhabit the interior rain forests of British Columbia and Idaho. Increases in moose (Alces alces) and white-tailed deer (Odocoileus virginianus) are leading to the unsustainable predation rates on caribou (Seip 1992, Latham et al. 2011). Recovery options for mountain caribou can be summarized into three interrelated approaches (Seip 2008). The first is to reduce or eliminate forest harvesting in caribou range because this activity increases forage for moose and deer. Forest harvesting also reduces the abundance of arboreal lichens that are the primary food for mountain caribou during winter. However, reducing forest harvesting will not prevent the imminent extinction of many caribou subpopulations (Wittmer et al. 2010) because of the existing legacy of forestry; it will take decades for natural succession to reduce forage for moose and deer. The second option is to directly reduce predator numbers. In numerous locations this approach has been 
78 shown to increase caribou vital rates and population trend (Bergerud and Elliot 1998, Seip 79 1992, Hayes et al. 2003, Hervieux et al. 2014). Predator reduction, however, must be 80 continuous because if the treatment is stopped, predator numbers recover quickly, as long as 81 their primary prey are still abundant (Ballard et al. 1987, Hayes et al. 2003). Predator control is 82 also much less acceptable to the public than it was in the past (Orians et al. 1997, but see 83 Boertje et al. 2010). The third option involves reducing the primary prey that supports predator 84 populations, under the premise that this action will indirectly reduce predator numbers.

Recent recovery actions across the range of mountain caribou have included protecting $86>2$ million hectares of old-growth forest from logging, closing areas to snowmobiling, and 87 adhering to a minimum distance between mechanized recreation and observed caribou. Yet, 88 because these management actions do not deal with proximate limiting factors, a population response from caribou has not been observed, even in herds that live in parks and have seen minimal disturbance on their range (Hebblewhite et al. 2010, Serrouya and Wittmer 2010). Viability analyses suggest that under current conditions, without any additional habitat degradation, many mountain caribou populations are on a trajectory to extinction (Wittmer et al. 2010). Clearly this means that direct management of animal populations is needed, and such actions should be implemented across broad spatial scales (Carpenter et al. 1995) that large mammal predator-prey systems are known to encompass (Hayes et al. 2003, Mosnier et al. 2008).

The hypothesis we tested was whether substantially reducing moose numbers, the wolves' (Canis lupus) primary prey in this ecosystem, to an ecological target (Serrouya et al. 2011) would reduce wolf populations and thus positively affect caribou population growth. The ecological target was based on the estimated number of moose that would exist if there had been no logging, which implied a reduction of $c .70 \%$ over contemporary numbers (Serrouya et al. 2011). Nested within our broad hypothesis were three more specific hypotheses, each contingent on the previous one: 1) sport hunting could be used to substantially reduce moose numbers; 2 ) wolves in the Columbia ecosystem were primarily limited by moose abundance; and 3) mountain caribou were partially limited by wolf predation. Theoretical underpinnings of the broad hypothesis were explored in Serrouya et al. (2015a) who found that the rate and 
107 intensity of reducing invading prey would have a major influence on the native prey. In this

108

109

110

111

112

113

114

115

116

117

118

119

120

121

122

123

124

125

126

127

128

129

130

131

132

133

134

135

paper we focus on empirical data including before-after control-impact (BACl) comparisons of large areas that were subject to the moose reduction, with a spatial reference area where moose were not reduced, and on the vital rates of the large mammals under study (caribou, moose, and wolves).

The ability to use sport hunting to reduce ungulate populations is important because hunter access and the fecundity rate of the prey species make some cervid populations resilient to increased hunting (Brown et al. 2000, Lebel et al. 2012, Simard et al. 2013). To properly test this hypothesis, we had to establish whether any change in moose abundance was caused by the change in harvest policy, or a broader ecological process such as climate/weather or ecosystem change that can also influence ungulate populations (Post and Stenseth 1998). The spatial reference area where moose hunting was not increased helped to resolve these potential confounds.

The hypothesis that wolves were primarily limited by moose abundance simply predicts that reducing moose will reduce wolf abundance. Descriptive studies from within the study area suggested that wolf diets were dominated by moose (Stotyn 2008), and across a variety of ecosystems there is a broad relationship linking ungulate biomass to wolf abundance (Fuller et al. 2003). However, wolf populations lag, sometimes by many years, in response to a decline in their primary prey (Mech 1977, Gasaway et al. 1983). In such a case, the ratio of wolves to prey would increase, at least temporarily, which could be detrimental to caribou because they would become a higher proportion of available prey. There is increasing evidence that higher predator to prey ratios translate to higher per capita predation rates (Vucetich et al. 2011). In addition, wolf populations may not track the availability of moose biomass, but instead respond to the abundance of vulnerable (old) moose (Peterson et al. 1998). These factors may result in an equivocal relationship between wolf abundance and the moose reduction treatment, particularly at a local scale.

The final hypothesis was that mountain caribou were limited in part by wolf predation (Wittmer et al. 2005a), and therefore our prediction was that reduced wolf numbers would at least increase caribou survival and reduce their rate of decline compared to before the 
136 treatment and to the spatial reference area. This hypothesis has received support across many 137 woodland caribou subpopulations, either through manipulation (Seip 1992, Hayes et al. 2003,

138 Hervieux et al. 2014) or mensurative experiments (Seip 1992, Rettie and Messier 1998,

139 McLoughlin et al. 2003, Wittmer et al. 2005b, Latham et al. 2011). We also predicted that

140 caribou recruitment would increase following the treatment, recognizing that caribou calves

141 might be killed by bears or meso-predators to a greater extent than wolves (Adams et al. 1995,

142 Gustine et al. 2006). Again, these predictions depended on the previous hypothesis, where a

143 reduction in wolves could be achieved by reducing moose.

144 STUDY AREA

145 The study was located within two major mountain ranges in the interior of British 146 Columbia, the Columbia and Cariboo Mountains. The treatment area was $6500 \mathrm{~km}^{2}$ whereas 147 the reference area was $11500 \mathrm{~km}^{2}$, and they were separated by the Monashee Mountains, a 148 sub-range of the Columbia's with a maximum elevation of $3274 \mathrm{~m}$. All these areas were 149 windward ranges of the Rocky Mountains that had wet climates dominated by interior rain150 forests. Both areas were rugged and remote. Half of the treatment area was on the west side of 151 Lake Revelstoke with only boat access (Fig. 1), and thus little human presence. In the reference 152 area there was a major highway and railway, whereas in the treatment area there was one 153 dead-end highway with relatively little traffic. Warm summers and cool, wet winters with 154 excessive snowfall ( $>20 \mathrm{~m}$ ) are typical in the central portion of these ranges at mid elevations (1800 $\mathrm{m}$ a.s.I.) where caribou spend most of the winter. In valley bottoms (400 - $500 \mathrm{~m})$ snowfall averages $396 \mathrm{~cm}(\mathrm{n}=100 \mathrm{yr}, \mathrm{SD}=120)$, which is where most other ungulates and their

157 predators spend the winter. As the snow melts in summer, moose and deer, along with wolves, 158 bears (Ursus spp.), and cougars (Puma concolor), spread out in the mountains. As a rough ratio of moose to deer abundance, sampling from 17 pellet transects cleared and measured each spring from 2003 to 2011 (Serrouya et al. 2011) recorded 969 moose and 61 deer pellet groups

161 (a ratio of 15.9:1).

162 Below approximately $1300 \mathrm{~m}$, western redcedar (Thuja plicata) and western hemlock

163 (Tsuga heterophylla) are the typical climax tree species, whereas above this elevation the forest 164 transitions to Engelmann spruce (Picea engelmannii) and subalpine fir (Abies lasiocarpa). 
165 Forest age classes are typically bi-modal, with either old ( $>250 \mathrm{yr}$ ) or young (<40 yr)

166 regenerating stands following harvesting, and relatively little (<15\%) mid-seral vegetation.

167 Natural shrub openings occur in avalanche paths, marshes, and at higher elevation as the forest 168 transitions to alpine areas.

169 The caribou subpopulations in the treatment area included Columbia North, Columbia

170 South, and Frisby-Queest. The latter two each numbered less than 50 caribou when the moose

171 reduction treatment began, while Columbia North numbered c.150 when the treatment began

172 (McLellan et al. 2006). A portion of the Frisby-Queest range was located in the reference area,

173 but the vast majority (> 80\%) of caribou occurrences from that subpopulation were located in

174 the treatment area (Apps et al. 2006). In the reference area, caribou subpopulations were Wells

175 Gray South and Groundhog, which numbered c. 120 and 20, respectively, at the beginning of

176 the experiment. Although Wittmer et al. (2005a) considered Wells Gray North and South to be

177 one subpopulation, more recent analyses revealed limited demographic exchange between

178 these areas (van Oort et al. 2011, Serrouya et al. 2012), so the comparison was limited to the

179 Wells Gray South portion (Fig. 1) of the larger Wells Gray subpopulation. 


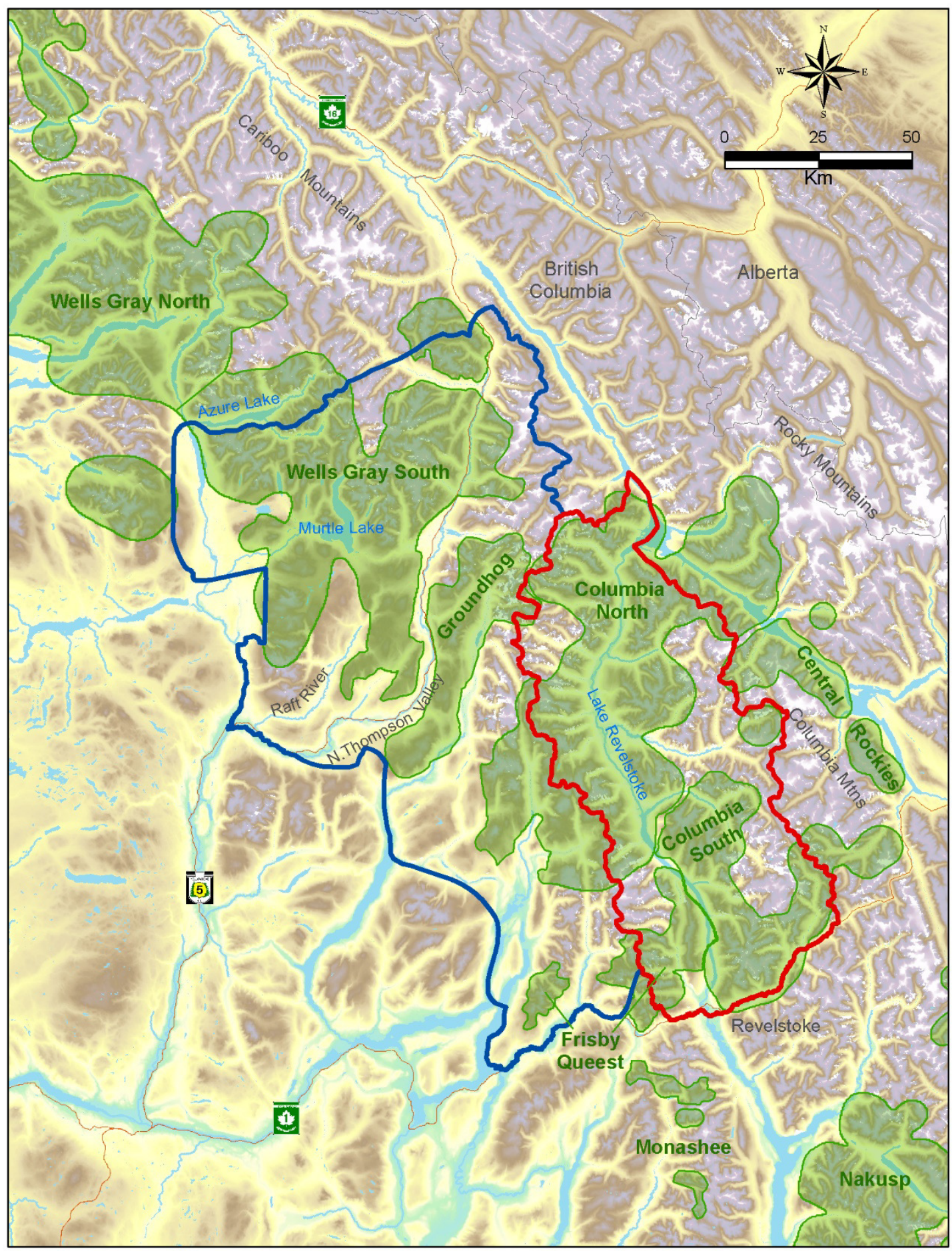

180

181

182

Figure 1. Map of treatment (red) vs. reference areas (blue). Caribou subpopulations are shaded green. 


\section{METHODS}

185

186

187

188

189

190

191

192

193

194

195

196

197

198

199

200

201

202

203

204

205

206

207

208

209

210

211

212

To estimate population size, trend, recruitment, survival, mortality causes and dispersal rates, animals were captured and fitted with VHF or GPS radio collars. Caribou and moose were captured by aerial net-gunning, whereas wolves were captured using leg-hold traps and netgunning. To reduce confounding effects of age for estimates of vital rates, we avoided capturing animals that were $<2$ years old (and to avoid risks with radio collaring). Net-gunning was conducted in winter when snow facilitated tracking and minimized the risk of injury to animals, whereas leg-hold traps were used in summer only. Captures adhered to BC Provincial Government and University of Alberta animal care protocols (permit \# VI08-49757, and 690905, 2004-09D, 2005-19D).

Animals were monitored every two to four weeks from fixed-wing aircraft using VHF telemetry. If an animal was not found during a monitoring session, the pilot (D. Mair, Silvertip Aviation) scanned for these animals while en route to other projects centered 150 to $300 \mathrm{~km}$ away in BC and Alberta, flying at a high altitude $(>2500 \mathrm{~m})$ to maximize collar detection. We occasionally searched a 50-100 km buffer around the study area using a meandering flight path to try to locate missing animals.

\section{Study design and response metrics}

The design was based on an ecosystem-level perturbation intended to reduce moose populations in one area (treatment) and compare the results to the reference area where no attempt was made to reduce the moose population. In the treatment area, a 10-fold increase in the number of moose hunting permits began in 2003 (Fig. 2; Serrouya et al. 2015b), but no major change in policy occurred in the reference area. In the treatment and reference areas we estimated moose survival and population trend, wolf survival and dispersal, and caribou survival, abundance, trend, and recruitment. In the treatment area alone, we also estimated wolf abundance, trend, and recruitment (Table 1). Caribou monitoring began in 1992 (summarized in Wittmer et al. 2005a), so we compared population parameters before and after the moose reduction treatment began, and against the spatial reference area, conforming to a $\mathrm{BACl}$ design. Moose abundance and survival estimates began in 2003, but population trend based on hunter harvest data could be estimated in both areas prior to this date. Wolf survival 
213 and dispersal comparisons began in 2004, but abundance estimates began in 2007. For moose

214 and wolves, we present animal abundance and density because density fluctuates within a year

215 as the available habitat changes 3-fold in summer vs. winter when snow restricts the

216 distribution of moose and wolves to the valley bottom. Winter densities can be obtained by

217 dividing abundance by c. $1100 \mathrm{~km}^{2}$, but summer densities are roughly 3-fold less as snow melts 218 and animals disperse into adjacent mountains (Serrouya et al. 2011).

219

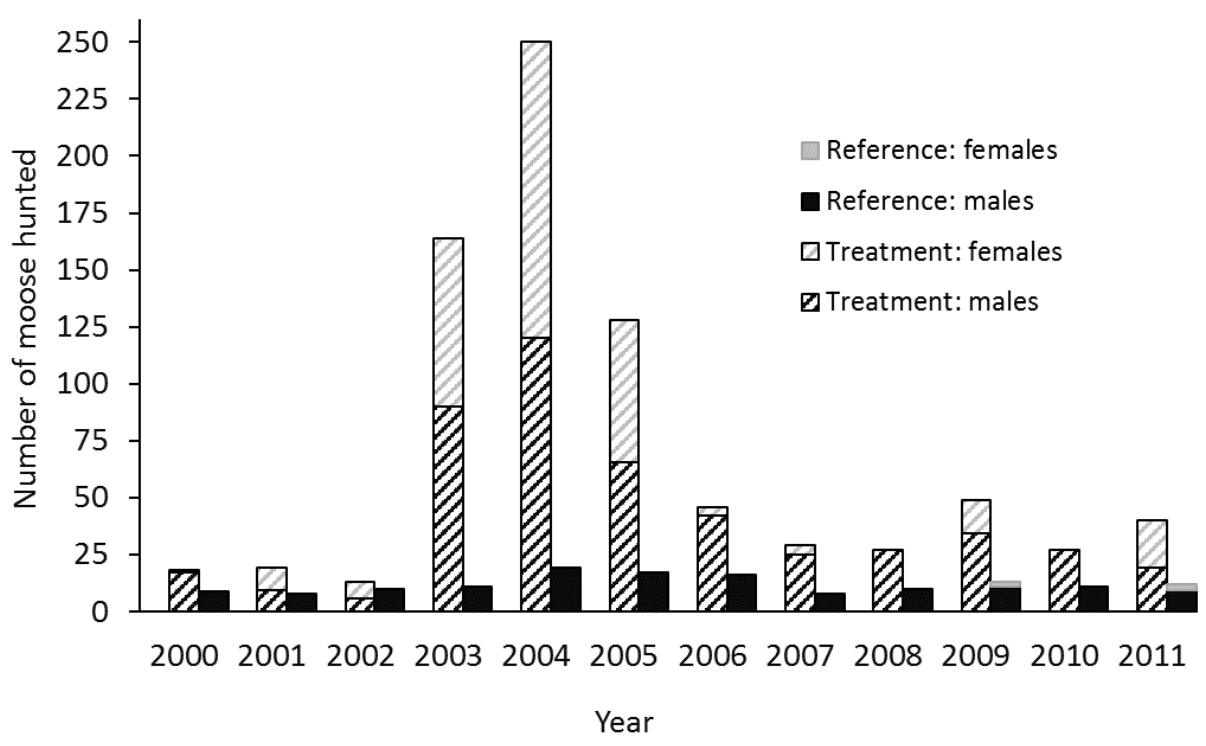

220

221

222

223

224

225

226

227

228
Figure 2. Number of moose harvested in the treatment and reference areas. The moose reduction treatment began in 2003. From Serrouya et al. (2015b).

Table 1. Response metrics within the treatment and reference areas (Yes $(\mathrm{Y})$ or No $(\mathrm{N}))$. $\mathrm{Y}$ in brackets also indicates whether data exist before the moose reduction treatment began (i.e. $\mathrm{BACl})$. 


\begin{tabular}{lll}
\hline Metric & Treatment & Reference \\
\hline & & \\
Wolf survival and dispersal & $\mathrm{Y}$ & $\mathrm{Y}$ \\
Wolf abundance & $\mathrm{N}$ & $\mathrm{N}$ \\
Wolf trend & $\mathrm{Y}$ & $\mathrm{N}$ \\
Wolf recruitment & $\mathrm{Y}$ & $(\mathrm{Y})$ \\
Moose trend & $\mathrm{Y}(\mathrm{Y})$ & $\mathrm{Y}$ \\
Moose abundance & $\mathrm{Y}(\mathrm{Y})$ & $\mathrm{Y}$ \\
Moose survival & $\mathrm{Y}$ & $\mathrm{Y}(\mathrm{Y})$ \\
Caribou abundance and trend & $\mathrm{Y}(\mathrm{Y})$ & $\mathrm{Y}(\mathrm{Y})$ \\
Caribou survival & $\mathrm{Y}(\mathrm{Y})$ & $\mathrm{Y}(\mathrm{Y})$ \\
Caribou recruitment & $\mathrm{Y}(\mathrm{Y})$ & $\mathrm{Y}$ \\
\hline
\end{tabular}

229

230

231

232

233

234

235

236

237

238

239

240

241

242

243

244

245

246

247

248

249

\section{Moose abundance, trend, and survival}

Methods to estimate moose abundance and trend were described in Serrouya et al.

(2011). Briefly, in the treatment area moose abundance was estimated using stratified random block aerial surveys (Gasaway et al. 1986) and trend was monitored using annual pellet transects (Serrouya et al. 2011). Catch per unit effort (CPUE) hunting data were calibrated against these values (Serrouya et al. 2015b) and compared to CPUE data from the reference area. In the reference area, moose abundance was estimated in 2007 in the northern third of the area (see reference area in Serrouya et al. 2015b), and in the Raft River in 2009 (Klafki et al. 2009). These two point estimates were not used to estimate population trend, which was estimated using CPUE data.

We calculated daily survival as 1 - (no. deaths) / (days monitored) for 2 risk periods: winter (i.e., Nov-Apr) and summer (May-Oct). To produce seasonal survival rates for winter and summer, we exponentiated daily survival rates by 181.25 for winter and 184 for summer (the no. of days in each period). We then calculated annual survival as the product of the 2 seasonal risk periods (Heisey and Fuller 1985). Several authors argue for alternative approaches such as cumulative incidence functions (Heisey and Patterson 2006, Murray 2006), but because we were not using any covariates to explain variation in survival, the Heisey-Fuller method was appropriate and is still commonly used in survivorship studies (Sparkman et al. 2011). To obtain $95 \%$ confidence intervals, we bootstrapped the distribution of animals 3000 times and used the percentile method. P-values for comparisons between areas were based on matching each 
250 bootstrap iteration from the treatment and reference, counting the number of times the

251 treatment values were greater, and converting this to a percentile.

252

253 Wolf abundance, trend, and vital rates

254 Wolf survival, dispersal, and cause-specific mortality rates were compared between the 255 treatment and reference (Table 1). These rates were estimated again using the Heisey-Fuller 256 method (Heisey and Fuller 1985), but relative to ungulates, wolf mortality patterns vary 257 unpredictably throughout the year. Therefore, to help reduce potential biases stemming from 258 changing mortality risk throughout the year, we chose 12 risk periods corresponding to each 259 calendar month, which converges to the Heisey-Patterson approach (Heisey \& Patterson 2006). 260 We again bootstrapped individual animals to obtain confidence intervals and $p$-values for 261 survival, cause-specific mortality rates, and dispersal rates. We also calculated an effective 262 survival rate by considering a dispersed animal to be "dead" from the study system. Cause263 specific mortality was separated into five categories: starvation, road kill, hunting and trapping, 264 predation, and unknown cause.

265 We defined dispersal as animals leaving the treatment or reference area by at least 50 $266 \mathrm{~km}$ and not returning by the time the study ended - which was the same as used in a similar 267 study conducted on the Parsnip caribou herd in central British Columbia (Steenweg 2011). 268 However, because the reference unit was substantially larger than the treatment unit, the 269 opportunity for dispersal in the reference area could be negatively biased. Therefore, we also 270 quantified a more conservative dispersal rate from the treatment unit, by simulating an 11.3

$271 \mathrm{~km}$ buffer around the treatment unit, which made it as large as the reference unit. The end 272 result was that in the treatment area wolves would have to disperse at least $61.3 \mathrm{~km}$ from the 273 edge. This adjustment was likely overly conservative, because the treatment area was bounded 274 by large mountains so if a wolf left this area it probably reflected an important decision to 275 expend energy and search for resources in a different area where its primary prey were not 276 declining rapidly. Dispersals included wolves that may have been lost from monitoring but were 277 subsequently found outside the study area (sensu Steenweg 2011, Webb et al. 2011) either 278 because they were harvested or were recaptured by another project. Potential dispersers were 
279 also estimated and included animals whose radio-signal was lost before the expected end of 280 the collar's life span (Mills et al. 2008, Steenweg 2011). Annual dispersal rates were calculated 281 independently from the other cause-specific rates because including dispersals would have 282 caused a negative bias in the other cause-specific rates (see equations in Heisey and Fuller 283 1985), particularly since emigrants are normally right censored from analyses. One annual risk 284 period was used to estimate the dispersal rates.

285 Wolf abundance and trend were estimated in two ways. From 2008 to 2014 each valley 286 below 1200 m elevation in the treatment area was surveyed within a short time frame ( $2-4$ 287 days). Surveys began one or two days after sufficient snowfall to allow fresh tracks to be 288 detected and easily counted. Helicopters were used extensively, but ground work was done 289 simultaneously on the east side of Lake Revelstoke. Flight paths focussed on areas where tracks 290 could be easily spotted such as forestry roads, cutblocks and wetlands. Ground transects were 291 surveyed using snowmobiles or trucks along plowed and unplowed roads. An attempt was 292 made to locate all wolves in the survey area by trailing each pack until the group size could be 293 counted or at least estimated from tracks. The 2007 estimate was based on an integrated count 294 from multiple data sources over the second half of the winter, including 7 track transects 295 sampled $2-3$ times, an aerial survey, ground observations, and GPS telemetry for 3 of the 6 296 packs to define pack boundaries. The aerial survey was not a complete census but focussed on counting members of the packs with collared animals and the 3 known packs without a collared member (sensu Hayes et al. 2003). This estimate was considered a minimum because only known packs with territorial animals were enumerated. When trailing wolves, a minimum estimate was always produced. These estimates were obtained from tracking evidence such as 301 splitting of routes followed, or from visual observations of the pack. A maximum estimate was also recorded which provided an upper limit for each pack. The maximum count was more 303 subjective than the minimum count. Each time we encountered a pack we checked for the presence of a collared wolf to estimate the proportion of wolves missed during our survey. This 305 method did not produce a sufficient sample to calculate a correction factor, but did provide an approximate detection rate for the survey method. 
Wolf recruitment was estimated only in the treatment area in 2010 and 2011 and was

308

309

310

311

312

313

314

315

316

317

318

319

320

321

322

323

324

325

326

327

328

329

330

331

332

333

334

335

contrasted between a high and a low moose density zone within the treatment area. Moose density was 2.2 -fold higher in the high zone (0.43 vs. $0.20 / \mathrm{km}^{2}$, summer density). The objective of this comparison was to determine if this difference in moose abundance was enough to observe a response in wolf recruitment (sensu Messier 1985). To estimate recruitment, we placed motion triggered cameras (Reconyx, Inc., Holmen, Wisconsin) within home ranges of wolves that were monitored using GPS collars. We focused on three wolf packs with existing or recent telemetry data, which allowed us to estimate the location of denning areas. We also placed cameras along known travel routes that were near den sites. Three to four cameras were placed within each territory, and were occasionally moved to help maximize detection of wolves. Commercial wolf urine and gland lure (Kootenay Brand Lures, Kimberly, BC) was placed near the cameras to slow wolf movements. Cameras were checked approximately once per month and lures were refreshed during these checks. Our metric of recruitment was the number of different pups recorded in the photographs, as a minimum estimate of the number of pups in the pack.

\section{Caribou population trends, abundance, and recruitment}

Caribou abundance, adult survival and recruitment estimates were compared across treatment and reference areas, and before and after the moose reduction was initiated. Caribou censuses were conducted every two years on average, from March to early April when they were high in the mountains and their tracks in open snowfields made them highly visible. Caribou sightability was positively correlated with snowpack depth $\left(r_{s}=0.96, p=0.002\right.$; Flaa and McLellan 2000). When snow depth exceeds $300 \mathrm{~cm}$ at $1800 \mathrm{~m}$ a.s.l. (which occurs most winters), sightability is $>90 \%$ (Serrouya et al. 2017). In the 1990s, a large sample of individuals marked with radio collars allowed researchers to correct for missed animals and estimate precision using program NOREMARK (details in Wittmer et al. 2005a). However, in years when the radiomarked sample was low (i.e., after 2003), the number of caribou observed was used as the estimate. In these years, caribou were not counted unless the snow depth reached $300 \mathrm{~cm}$. Caribou trend was quantified using the finite rate of change (Caughley 1977), also termed lambda $(\lambda)$. 
337 adult sex ratios without undue harassment. Ungulate recruitment has high inter-annual

338 variability (Gaillard et al. 1998) so there is little reason to believe that serial autocorrelation is

339 important, and we grouped recruitment data before and after the treatment, again reducing

340 the need to correct for autocorrelation. We used a linear mixed-effects model (LME) to test

341 whether recruitment changed after the treatment, by creating a variable with two levels

342 (before, after), and evaluated this effect separately in the treatment and reference area.

343 Caribou subpopulation was specified as the random intercept. Recruitment was converted from

344 a proportion using the logit link for LME analyses. Because some populations declined

345 dramatically over the monitoring period, it may be appropriate to correct for population size

346 when estimating recruitment, so that estimates from populations with very few numbers carry

347 less weight. Therefore, we repeated the previous analysis but weighted the model by

348 population size.

\section{RESULTS}

350 Moose abundance, trend, and survival

351 The moose population in the treatment area declined by $71 \%$ from 2003 when

352 increased hunting began to $2014\left(\lambda_{\text {annual }}=0.86\right.$; Fig. 3). The average winter density across the

353 treatment area declined from $1.58 / \mathrm{km}^{2}$ to $0.44 / \mathrm{km}^{2}$ (1650 to 466 moose). However, the

354 detectable decline likely began 1-2 years after the treatment was initiated (Fig. 3), so before-

355 after analyses were centered on 2004. The reference area also demonstrated a declining

356 moose trend, but the magnitude was much less than the treatment area. The CPUE data

357 revealed that the slope of decline was more than five times greater in the treatment compared

358 to the reference area (slopes were -6.88 [-9.02 to $-4.68,95 \% \mathrm{Cl}]$ compared to $-1.32[-2.46$ to -

359 0.265]; Appendix 1). From 2003 to 2009, annual adult moose survival in the treatment area was

$3600.803(0.688$ to $0.895, N=54)$ and $0.878(0.727$ to $0.972, N=13)$ in the reference area $(P=$

361 0.18). Detailed mechanisms of the moose population decline in the treatment area were

362 presented in Serrouya et al. (2015b). 
363

364

365

366

367

368

369

370

\section{Wolf dynamics}

372

373

374

375

376

377

378

379

380

381

382

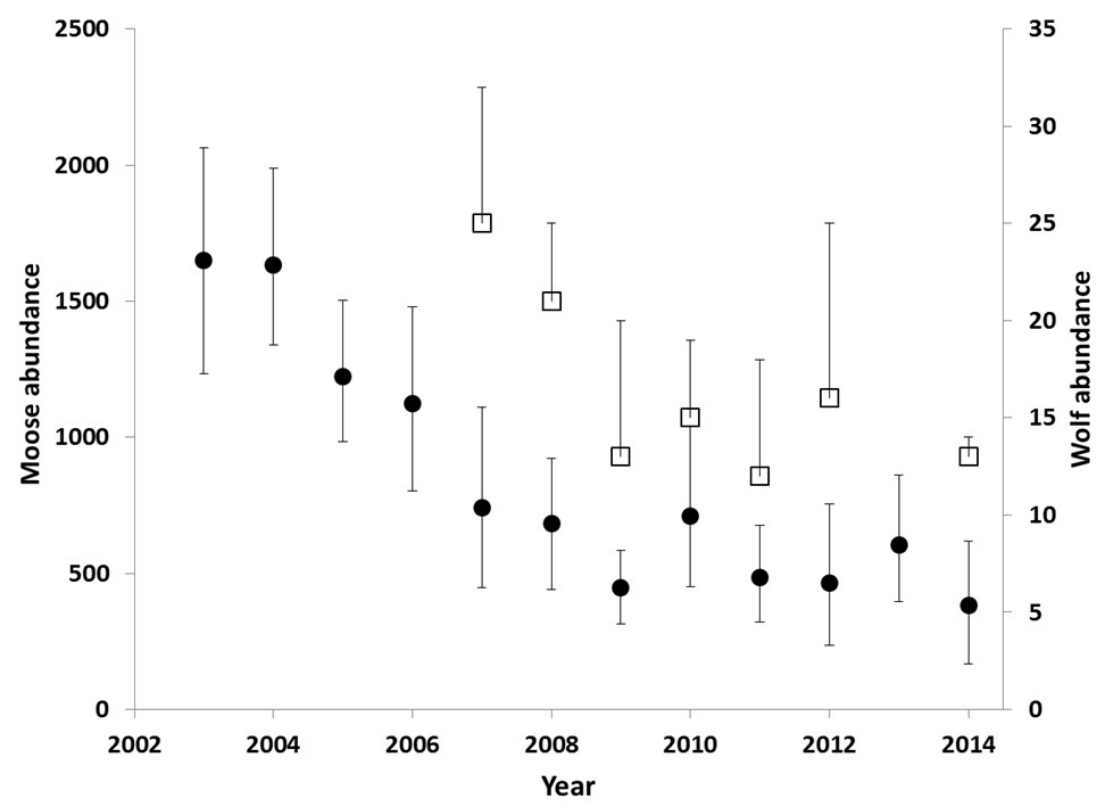

Figure 3. Moose (circles) and wolf (squares) abundance in the treatment area. Error bars for the moose estimates represent $90 \% \mathrm{Cls}$. The upper error bar for the wolf estimate show the maximum estimate, including a buffer around the treatment area. The square represents a minimum estimate. Between 1994 and 2003 the moose population was estimated to have doubled (Serrouya et al. 2011). Data updated from Serrouya et al. (2015a).

From 2004 - 2010, 63 different wolves were captured on 82 separate occasions. Five wolves were not located after capture and collar failure was suspected (they were GPS collars) so were excluded from analyses. Therefore, 58 wolves were available for survival and dispersal analyses; 34 in the treatment area and 24 in the reference area, with the sex ratio evenly split in both areas. This sampling covered 32.4 monitoring years in the treatment, and 22.2 years in the reference area. There were 12 mortalities of wolves collared in the treatment area. One died after dispersing and was not monitored during the intervening period so it was right censored. Another was a management removal and was also right censored. Eight of 34 (23.5\%) wolves dispersed from the treatment area, compared to 2 of 24 (8.3\%) in the reference area. If the larger buffer $(61.3 \mathrm{~km})$ is considered, then the number of confirmed dispersers from the treatment is reduced from 8 to 7. One additional wolf left the treatment area by crossing west over the Monashee Mountains, but then shed its collar. Because it was only 10 
$384 \mathrm{~km}$ from the edge of the treatment area it was not counted as a disperser. However, this wolf

385

386

387

388

389

390

391

392

393

394

395

396

397

398

399

400

401

402

403

404

405

406

407

408

409

410

411

was likely eating little based on kill rate estimates (Serrouya 2013), and may have crossed the mountains in search of higher moose abundance and could be considered a disperser. If potential dispersers are included (those whose radio signals were lost unexpectedly), then 13 of $34(38.2 \%)$ and 6 of 24 (25\%) wolves dispersed from the treatment and reference areas, respectively. These dispersal values are presented as annual rates in Table 2.

In the reference area there were eight mortalities, including two wolves that dispersed prior to dying (and were right censored for mortality estimation), and no other dispersals were recorded. Thus, in total, eight animals either dispersed or died from the reference area. Survival rates for the two areas were similar $(0.726$ [0.58 -0.85] vs. 0.757 [0.56-0.92]; Table 2). In the treatment area, two wolves from separate packs starved and one was killed by other wolves. Two non-collared wolves from different packs were also found to have starved in the treatment area. One was a pup found at the den site of the collared female that had starved. The other was a subordinate male that starved weeks after its collared pack-mate starved. Human-caused mortality rates (road kills, trapping and hunting) summed to 0.243 in the reference area but 0.129 in the treatment area (Table 2).

There was a minimum of 25 wolves in the treatment area in 2007, but evidence from the integrated count suggests that 32 individuals was more likely and was considered the maximum estimate for that year (Fig. 3). Populations were lower and stable from 2009 to 2014, with 2014 having the lowest maximum estimate (14). From $2008-2012$, all collared packs ( $n=$ 7) were detected during the survey (no collars were on air in 2014).

Wolf recruitment was higher in the high moose density zone in both 2010 and 2011 (Table 3). Sample sizes were small however (one pack in the high and two packs in the low zone), so no statistics were performed. In 2011, photos from the end of September suggested that the eight pups seen in July for the pack in the high density zone were reduced to four pups. Similarly, the pups seen from the Bigmouth and Red Rock packs earlier in the summer were absent from photos in September that included adult wolves. 
412 Table 2: Annual survival, mortality, and dispersal rates (95\% Cls) for wolves in the treatment

413 and reference areas. Effective survival considers animals that dispersed to equal death from the 414 area. P-values were calculated based on a bootstrap comparison of the difference between the 415 two areas.

\begin{tabular}{llllll}
\hline Parameter & Treatment & $\mathrm{N}$ & Reference & $\mathrm{N}$ & P-value \\
\hline Survival & $0.726(0.58-0.85)$ & 34 & $0.757(0.56-0.92)$ & 24 & 0.62 \\
Road kill & $0.024(0-0.07)$ & 1 & $0.082(0-0.21)$ & 2 & 0.78 \\
Hunt / Trap & $0.105(0.02-0.21)$ & 4 & $0.162(0.04-0.33)$ & 4 & 0.74 \\
Starvation & $0.063(0-0.17)$ & 2 & 0 & 0 & $\mathrm{NA}$ \\
Predation & $0.028(0-0.09)$ & 1 & 0 & 0 & $\mathrm{NA}$ \\
Unknown & $0.053(0-0.13)$ & 2 & 0 & 0 & $\mathrm{NA}$ \\
Dispersal & $0.221(0.09-0.39)$ & 8 & $0.087(0-0.22)$ & 2 & 0.08 \\
Dispersal (max) $^{\mathrm{a}}$ & $0.333(0.19-0.50)$ & 13 & $0.239(0.08-0.43)$ & 6 & 0.20 \\
Survival (effective) & $0.513(0.38-0.63)$ & 34 & $0.586(0.37-0.77)$ & 24 & 0.73 \\
\hline
\end{tabular}

416

417

418

419

420

421

422 423

(L) (summer density estimates).

\begin{tabular}{|c|c|c|c|c|c|c|}
\hline \multirow[b]{2}{*}{ Pack } & \multirow[b]{2}{*}{ Zone } & \multicolumn{2}{|c|}{ Pups } & \multirow{2}{*}{$\begin{array}{l}\text { No. cameras } \\
\text { Sites }\end{array}$} & \multirow{2}{*}{$\begin{array}{l}\text { Trap } \\
\text { Nights }\end{array}$} & \multirow{2}{*}{$\begin{array}{l}\text { Photos } \\
\text { with } \\
\text { wolves }\end{array}$} \\
\hline & & 2010 & 2011 & & & \\
\hline Gothics & $\mathrm{H}$ & 3 & 8 & 7 & 727 & 208 \\
\hline Bigmouth & $\mathrm{L}$ & $1^{b}$ & 2 & 6 & 583 & 49 \\
\hline Red rock & $\mathrm{L}$ & 0 & $1^{a}$ & 7 & 706 & 158 \\
\hline
\end{tabular}

424

a This pup was not recorded in the camera traps but was observed alone while deploying a

425

426

427

428

429

430

431

Table 3. Highest number recorded of pups in the treatment area during the summer months using remote cameras in three different wolf territories within two zones of moose density. Moose density was approximately $0.43 / \mathrm{km}^{2}$ in the High zone $(H)$ and $0.20 / \mathrm{km}^{2}$ in the Low zone camera trap along a logging road.

b This pup was found dead at the den site with its collared mother, which also appeared to starve.

\section{Caribou abundance, recruitment and survival}

The two smaller caribou populations in the treatment area (Columbia South and FrisbyQueest) continued to decline after the treatment was initiated (Fig. 4). The rate of decline 
432 increased for Columbia South, and remained steady for Frisby-Queest $(\lambda=0.92-0.94)$. The

433 growth rate of the largest subpopulation in the treatment area, Columbia North, increased

434 following the moose reduction (Fig. 4), though that increase was primarily because of the 2013 435 estimate, with 32 additional animals compared to the 2011 estimate. In the reference area, the 436 smaller subpopulation (Groundhog) continued to decline, and the Wells Gray South

437 subpopulation initially appeared to stabilize but a marked reduction was observed in 2013 (Fig.

438 4). After moose were reduced, adult caribou survival increased from 0.784 to a high of 0.879 in 439 the treatment area (Columbia North subpopulation, pooled P-value $=0.11$ ), but declined in the 440 reference area (Wells Gray subpopulation; P < 0.02; Table 4).

441

442

443 Table 4. Survival of radio-marked adult caribou in the treatment and reference area, both 444 before and after the treatment began (pre and post 2004, respectively). $\mathrm{N}$ is the number of 445 caribou monitored during the time period. For this comparison, the treatment area included the Columbia North subpopulation, and the reference area was the Wells Gray subpopulation.

\begin{tabular}{|c|c|c|c|c|c|c|}
\hline \multicolumn{4}{|c|}{ Treatment area } & \multicolumn{3}{|c|}{ Reference area } \\
\hline Time period & Survival & & $\mathrm{N}$ & Time period & Survival & $\mathrm{N}$ \\
\hline \multicolumn{7}{|c|}{ Before treatment } \\
\hline 1996-2002 & 0.793 & $(0.697-0.873)$ & 40 & \multirow{2}{*}{ 1997-2004 } & \multirow{2}{*}{$0.868(0.801-0.923)$} & \multirow{2}{*}{39} \\
\hline 2002-2004 & 0.784 & $(0.556-0.944)$ & 17 & & & \\
\hline \multicolumn{7}{|c|}{ After treatment } \\
\hline 2004-2006 & 0.879 & $(0.731-1.0)$ & 14 & \multirow{2}{*}{ 2004-2010 } & \multirow{2}{*}{$0.725(0.531-0.851)$} & \multirow{2}{*}{15} \\
\hline $2006-2008$ & 0.857 & $(0.676-1.0)$ & 10 & & & \\
\hline
\end{tabular}

447

448

449

450

There was no indication that caribou recruitment improved as a result of the treatment

451 (LME $\beta_{\text {before }}=0.456, S E=0.32, p=0.17, n=30,3$ groups; Fig. 5). The predicted value of

452 recruitment was $15.5 \%$ (before) vs. $10.1 \%$ (after), and if the analysis was weighted by

453 population size then the values changed little, to 14.3 and $11.5 \%$, respectively. Recruitment

454 improved in the reference area after the treatment began ( $\operatorname{LME} \beta_{\text {before }}=-0.380, \mathrm{SE}=0.15, \mathrm{p}=$

$4550.02, n=20,2$ groups; 13.1\% (before) vs. 18.1 (after); Fig. 5), but when population size was 
456 accounted for the difference was negligible (14.8\% to $16.3 \%)$, and non-significant $(p=0.38)$

457 likely because the high recruitment value (33\%; Fig. 5) from Groundhog in 2011 was discounted 458 due to its much reduced population size ( $n=9$; Fig. 4).

459
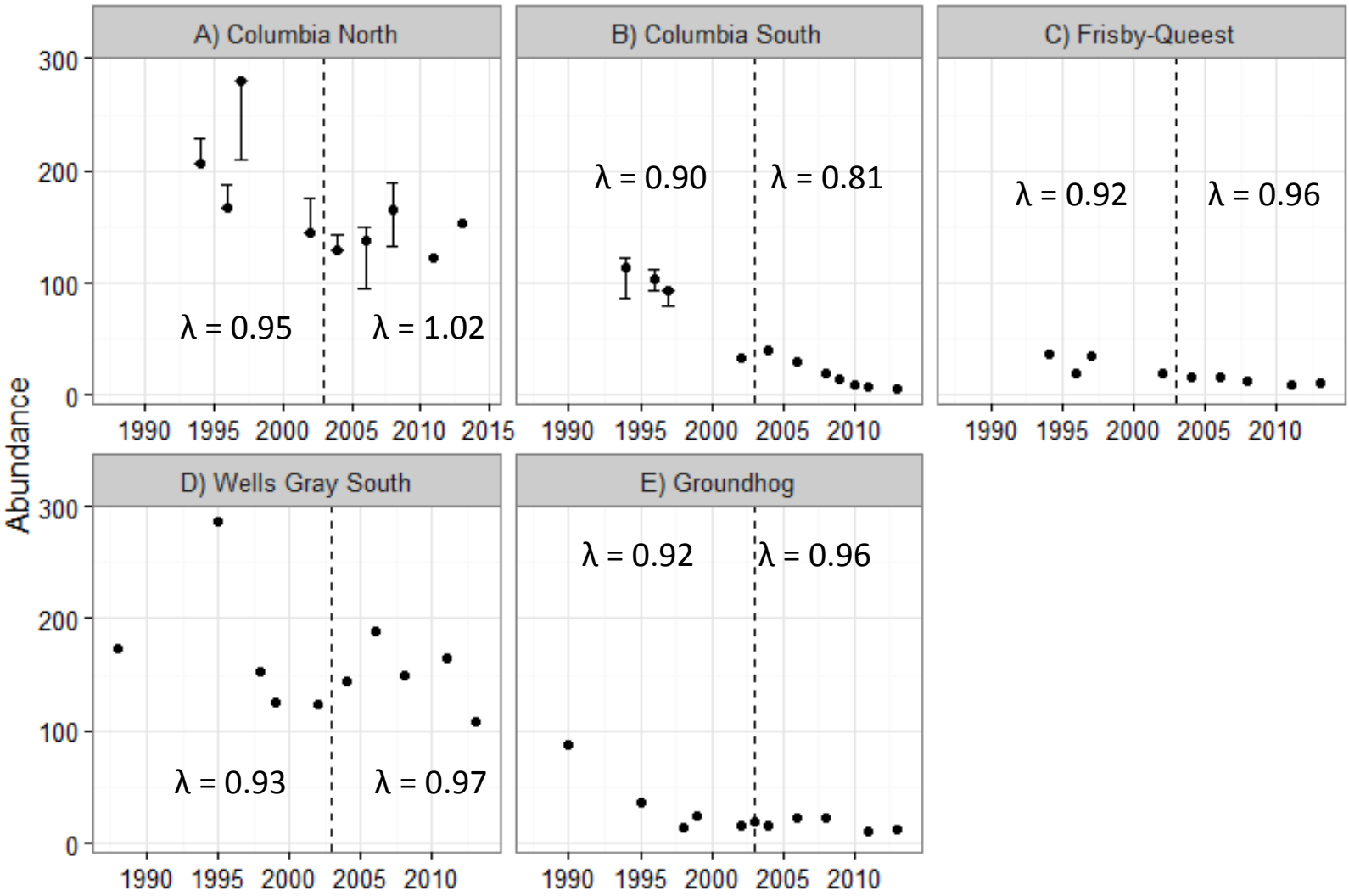

19901995200020052010

460

461

462

463

464

465

466

467

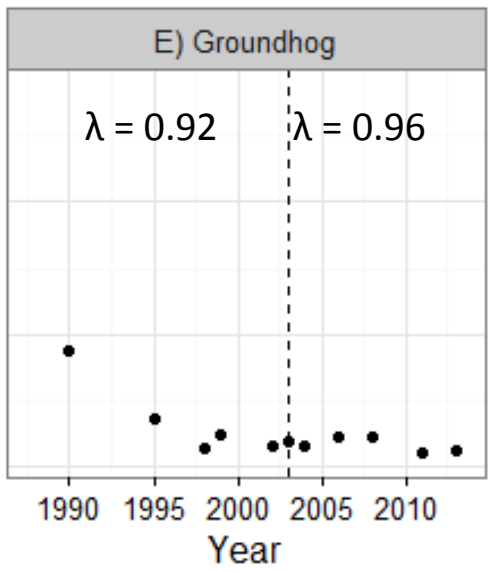

Figure 4. Caribou population estimates for five subpopulations, three in the treatment area (A - C; top row) and two in the reference area (D, E; bottom row). Error bars are $95 \% \mathrm{Cls}$. The dashed vertical line represents the beginning of the moose reduction treatment in 2003. Lambda values to the left of the dashed line represent the years 1994 to 2004 whereas those to the right of the line represent the years 2004 to 2013. Data updated from Wittmer et al. (2005a). 


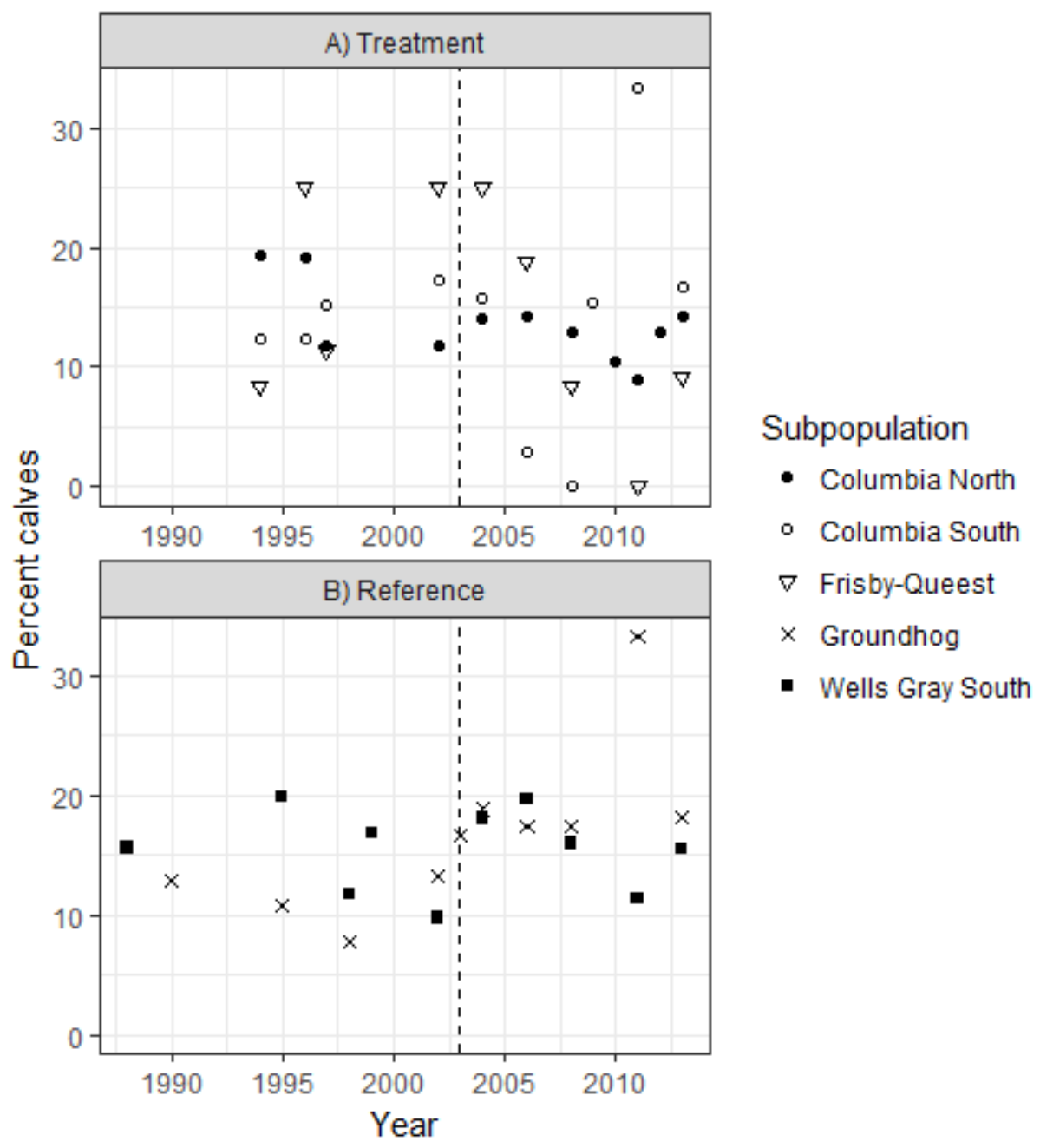

468

469

470

471

472

473

474

475

476

477

478

479

Figure 5. Caribou recruitment (\% calves) within the treatment $(A)$ and reference areas (B). The vertical line represents when the moose reduction began in the treatment area. Symbols represent separate subpopulations.

\section{DISCUSSION}

The primary hypothesis tested was that reducing moose abundance to an ecological target would reduce the caribou's rate of decline. Within this hypothesis were three nested hypotheses and predictions. The first of these was confirmed: moose were reduced using sport hunting and two lines of evidence support this conclusion. First, the population declined at a rate that was 5 -fold greater than in a spatial reference area where the hunting kill was not increased. Second, we contrasted the effects of hunting compared to predation and found that 
480 both factors contributed to the decline, with the increased hunt initiating the depensatory 481 predation rate observed in the treatment area (Serrouya et al. 2015b). It may seem intuitive 482 that increasing hunting pressure on a large herbivore would reduce its abundance, particularly 483 with more females harvested. However, other North American cervids have been difficult to 484 control using sport hunting (Brown et al. 2000, McDonald et al. 2007, Simard et al. 2013) 485 because of poor access, urban refuges (Polfus and Krausman 2012), or high fecundity and 486 immigration rates. In one of the few other experimental attempts to reduce an overabundant 487 ungulate, Simard et al. (2013) found that white-tailed deer were not reduced in replicated 20$488 \mathrm{~km}^{2}$ treatments on a predator-free island. Moose are less fecund than white-tailed deer, which 489 may explain the discrepancy between the two systems. Furthermore, our treatment area was 300 times larger, with less chance of immigration because of the closure imposed by rugged mountain ranges.

The second of the nested hypotheses was that wolves were primarily limited by moose abundance, with the prediction that reducing moose would reduce wolf numbers. Ostensibly, this hypothesis appears trivial because of established relationships between ungulate biomass and wolf abundance (Fuller et al. 2003), but complimentary explanations have been proposed related to the age or vulnerability of moose, or social constraints within wolf packs that limit wolf abundance regardless of food availability (Messier 1994, Peterson et al. 1998, Hebblewhite 2013, Cubaynes et al. 2014). This hypothesis was also supported, because wolf numbers declined following the moose reduction. The lack of wolf survey data prior to 2007 weakens this conclusion, as does the absence of trend data of wolves in the reference area. Nonetheless, we identified several mechanisms to explain the reduction in wolf abundance. First, the dispersal rate was greater in the treatment area than the reference area, resulting in a relatively low effective survival rate. At 0.51 , the effective survival rate was lower than the minimum level 504 (0.64) required to maintain a stable wolf population (Fuller et al. 2003). These results mirror 505 those of Steenweg (2011) who found dispersal to be the primary wolf vital rate affected by a moose reduction treatment in the Parsnip area. The dispersal rate in our treatment area was

507 also greater than what was estimated by Webb et al. (2011), who reported an emigration rate 508 of 0.13 in a population in Alberta. Second, we found some evidence of reduced wolf 
509 recruitment in areas with lower moose densities $\left(0.2 / \mathrm{km}^{2}\right)$. Messier (1985) also found that at 510 moose densities $<0.2 / \mathrm{km}^{2}$, wolves had difficulty recruiting pups. Third, wolf starvation was

511 recorded in the treatment area but not the reference area. Finally, analyses of wolf scat 512 contents showed that wolves were primarily supported by moose in this study area (Stotyn

5132008 , Serrouya 2013) so a reduction in wolf numbers is consistent with a reduction in their 514 major food source.

$515 \quad$ Although trappers removed wolves in the area, the overall trapping and hunting rate 516 (0.11) is low compared to other populations. In Alberta, Webb et al. (2011) estimated that a 517 harvest rate of 0.34 had no effect on the population trend of wolves. Few wolves were trapped 518 or hunted in the study area because the amount of snowfall confounds trap sets and thick 519 cover obscures visibility for hunting. Therefore, changes in wolf abundance can be attributed to 520 a reduction in food and not intensive human harvest.

521 The final hypothesis, that reduced wolf numbers would lessen the rate of caribou 522 decline relative to spatial and temporal contrasts, was partially supported. The three smallest 523 caribou populations continued to decline, regardless of whether they were in the treatment or 524 reference area. A number of mechanisms can negatively affect small populations including 525 environmental stochasticity and Allee effects (Allee 1931) resulting from predation, and both of 526 these processes have affected woodland caribou (Hebblewhite et al. 2010, McLellan et al.

527 2010). We acknowledge that only the largest of 3 subpopulations subjected to the moose 528 reduction demonstrate improved demographic trend. However, a parallel study in the Parsnip 529 region showed similar improvement to caribou populations when moose were experimentally 530 reduced (Steenweg 2011; Heard, D. unpublished data).

531 For the two largest subpopulations (Columbia North and Wells Gray), a modest increase 532 was observed in the treatment area (Columbia North) but a sharp decline in the reference area 533 (Wells Gray). It is tempting to conclude that the experiment was not a success because caribou 534 population growth was not immediate and pronounced in the treatment area. However, our 535 results are similar to other management actions intended to recover declining caribou herds. In 536 Alberta, 841 wolves were removed in a caribou range from 2005 to 2012 and resulted in 537 caribou $\lambda$ increasing from 0.950 .99 (Hervieux et al. 2014). Similarly, a moose reduction in the 
538 Parsnip area resulted in $\lambda$ of caribou increasing from 0.95 to 1.02 (Steenweg 2011; Heard, D. 539 unpublished data). These actions have not rapidly recovered caribou populations but the

540 resulting trends are an improvement over the alternative, continued population declines.

541 Formal caribou population comparisons from this study ended in 2013 because a maternity pen

542 (a pilot trial of in situ captive breeding designed to increase calf survival) was initiated in the

543 Columbia North subpopulation that year, which could confound results of the moose reduction.

544 However, the 2017 caribou census for Columbia North revealed a count of 147 caribou, still 545 higher than 2003, and 5 fewer than 2013, indicating at least stability from 2003 to 2017. The

546 population effect of the maternity pen pilot trial was likely negligible (estimated to have added

547 a net of 8 calves over 3 years; Legebokow and Serrouya 2017), meaning that 14 years of

548 population stability can likely be attributed to the moose reduction.

549 In our experiment, moose numbers were reduced using a change in hunting regulations, 550 addressing a more ultimate cause of the apparent competition problem, rather than direct wolf 551 control. Yet, because moose were not reduced to the target developed by Serrouya et al. (2011; $552 \sim 300$ moose), or even to the lower range of the predicted target (lower 95\% Cl: 167 moose), 553 the caribou response was unlikely as strong as anticipated. Prior to the 1940 s, moose were at 554 even lower densities than predicted by Serrouya et al. (2011) and may have been absent from 555 central and southern BC (Spalding 1990, Kay 1997, Santomauro et al. 2012). The precautionary principle (Doak et al. 2008) would suggest reducing moose even lower than 300 to hold wolves at lower numbers. Recent wolf densities in winter are $c .13 / 1000 \mathrm{~km}^{2}$, which is above a target

558

559

560

561

562

563

564

565

566 developed by Bergerud and Elliot (1986), who found that caribou mortality was offset by recruitment at the threshold of 6.5 wolves $/ 1000 \mathrm{~km}^{2}$. Prey switching by wolves from moose to caribou could also be invoked to explain the lack of caribou population growth. However, an analysis of wolf scats suggests that prey switching did not occur (Serrouya 2013), given that moose were gradually reduced over 10 years. When prey are reduced suddenly, prey switching becomes a greater risk (Serrouya et al. 2015a) and can exacerbate caribou declines.

In most ungulate systems adult survival is necessarily high (Gaillard et al. 1998), making statistical comparisons ( $p<0.05$ ) difficult (McLellan et al. 1999, Hayes et al. 2003). This pattern is also true of endangered species or low-density carnivores where large sample sizes are 
567 challenging to obtain. However, in the ecological literature there is increasing emphasis placed

568 on stressing the magnitude of biological effects (Burnham and Anderson 2002). In our case,

569 there was a substantial increase in caribou adult survival in the treatment area ( 8.5 units;

570 Table 4), enough to considerably affect population growth (DeCesare et al. 2012, Serrouya et al.

571 2017). The same pattern occurred for other vital rates such as moose survival (7.5 units lower in

572 the treatment area) and wolf dispersal ( $2.5 \times$ greater in treatment area), with $p$-values

573 approaching statistical significance but the magnitude and direction of estimates supporting the 574 primary hypotheses in this study. Caribou recruitment appeared unaffected by the moose

575 reduction treatment, likely because bear predation, not wolves, is a major limitation on caribou 576 calves (Brockman et al. 2017). Furthermore, calf recruitment in ungulates is highly variable

577 (Gaillard et al. 1998) and affected by many factors including spring weather (Hegel et al. 2010),

578 so a reduction in wolves may be less likely to clearly affect this age class compared to adult

579 survival, which is relatively unaffected by abiotic factors (Gaillard et al. 1998).

580 Spatial and temporal variation in predation intensity has a major influence on

581 population dynamics (Creel and Winnie 2005). Predation on adult mountain caribou by wolves

582 or cougars shifts from predominantly wolves in northern areas to cougars in southern areas

583 (Wittmer et al. 2005a). Bears were the second highest source of mortality in each of the

584 southern and northern half of caribou range, but with both areas combined, they were the

585 primary source of mortality. Furthermore, bears are a major predator of woodland caribou

586 calves (Adams et al. 1995). McLellan (2011) and Mowat et al. (2013) found grizzly bear densities

587 inversely related to terrestrial meat in their diet and more closely linked to vegetative food,

588 mostly fruit production (McLellan 2015) and, grizzly bears appear to eat little meat in our study

589 area (Hobson et al. 2000). Because bear foraging is directed at vegetation, we did not expect a

590 numerical response of bears to the moose reduction treatment. Cougar abundance and diets

591 were monitored intermittently in the treatment area (Bird et al. 2010) using GPS cluster

592 analyses (Anderson and Lindzey 2003, Knopff et al. 2009), with moose comprising 5 - $43 \%$ of

593 individual cougar diets (Bird et al. 2010). Cougar predation on caribou began following the peak

594 and collapse of deer populations (Serrouya et al. 2015a). After this dynamic, cougar numbers

595 declined and wolf predation on caribou increased (Stotyn 2008). These examples illustrate how 
596 conclusions drawn from landscape-level field experiments must consider how limiting factors 597 change, often unpredictably, over space and time (Doak et al. 2008). Nonetheless, by 598 combining what was observed in this and other case studies (Courchamp et al. 2003, Wittmer 599 et al. 2013), some generalities are supported. In the context of apparent competition, high but 600 especially fluctuating populations of primary prey can enhance extinction risk for rare prey 601 (Serrouya et al. 2015a). Maintaining lower and thus more stable populations of primary prey is 602 expected to reduce predator switching and help maintain predators at low numbers (Serrouya 603 et al. 2015a). This generality is likely applicable to other caribou systems where moose are not 604 the dominant ungulate biomass, but where other ungulates are expanding because of changing 605 land uses and climates.

606 Wolves are highly mobile and fecund, so if their primary prey remain abundant during a 607 period of wolf control, ingress occurs rapidly (Ballard et al. 1987, Hayes et al. 2003, Mosnier et 608 al. 2008). Therefore, at least an $80 \%$ annual reduction in wolf abundance is required to elicit a 609 response in ungulate population growth (Hayes et al. 2003). However, if wolf control were to 610 be implemented concurrently with primary prey reduction, it would likely have to be less 611 intensive and less continuous relative to other areas where primary prey was not reduced (e.g., 612 Yukon: Hayes et al. 2003; Quebec: Mosnier et al. 2008; Alaska: Gasaway et al. 1992; British 613 Columbia: Bergerud and Elliott 1998; Alberta: Hervieux et al. 2014).

614 In addition to this study, we are aware of three other attempts to reduce apparent 615 competition by reducing primary prey: 1) the Parsnip study; 2) a study where 25000 domestic 616 sheep were reduced to 2000 to try and recover endangered huemul deer (Hippocamelus 617 bisulcus) in Patagonia (Wittmer et al. 2013a,b); and, 3) the removal of feral pigs to recover the 618 island fox (Urocyon littoralis) on the Channel Islands of California (Courchamp et al. 2003), 619 although periodic predator removal of golden eagles (Aquila chrysaetos) also occurred in that 620 case. In a fourth study, a serendipitous experiment occurred when extensive poaching of 621 African buffalo (Syncerus caffer) was linked to reduced lion (Panthera leo) numbers, resulting in 622 a pronounced increase of impala (Aepyceros melampus; Sinclair 1995). In the Parsnip study, 623 results were similar to ours, with high wolf dispersal rates, and the caribou population 624 stabilized. In the case of huemul, their decline was exacerbated as a result of increased 
625 predation by foxes (Lycalopex culpaeus) and pumas (Puma concolor), likely resulting from the 626 abrupt decline in sheep and predators switching to huemul. The results of these manipulations 627 suggest inconsistent responses to reducing primary prey as a recovery tool for species affected 628 by apparent competition. This conclusion will complicate the decision-making process for 629 management agencies, but evidence suggests that this approach should be considered when 630 used in concert with tools that address other proximate and ultimate limiting factors.

631

632

633

634

635

636

637

638

639

640

641

642

643

644

645

646

647

648

649

650

651

652

Historical accounts (Spalding 2000, Seip 1992) suggest that mountain caribou were once at least an order of magnitude more abundant than they are today. During this period of caribou abundance, it is possible that the trophic interactions were reversed, and moose were the victim of apparent competition with wolf predation and harvest by First Nations (Kay 1997) keeping them at low numbers. Extensive wolf control using poison and bounties occurred from 1906 - 1962 throughout BC (McLellan 2010), and this along with climate and ecosystem change made it possible for moose to expand into southern BC. It is becoming increasingly evident that returning to the caribou-dominated system will require exceeding the biological population targets proposed by Bergerud and Elliot (1986) and Serrouya et al. (2011). Random processes associated with small populations, and Allee effects due to predation (McLellan et al. 2010, Armstrong and Wittmer 2011) will make it increasingly difficult to recover mountain caribou populations. However, an emerging pattern is that single management actions may halt declines, but multiple actions that address several limiting factors simultaneously will be required to achieve population growth (Serrouya 2013, Boutin and Merrill 2015).

\section{Acknowledgements}

We thank the Selkirk College Geospatial Research Centre for providing the radio collars for moose survival estimation. Dave Mair of Silvertip Aviation piloted our telemetry flights and Clay Wilson of Bighorn Helicopters helped to catch most of our animals. Leo DeGroot, Cory Legebokow, Tara Szkorupa, Chris Ritchie, and John Surgenor helped with many logistical aspects. Kelsey Furk and Janice Hooge assisted with telemetry flights, and Dale Seip provided constructive comments on previous versions of this manuscript. This research is dedicated to 
653 the memory of our friend and teacher, Gary Pavan, who was instrumental to the completion of 654 this project. 
655

656 LITERATURE CITED

657 Adams, L. G., F. J. Singer, and B. W. Dale. 1995. Caribou calf mortality in Denali National Park, 658 Alaska. Journal of Wildlife Management 59:584-594.

659

Allee, W. C. 1931. Animal Aggregations. University of Chicago Press, Chicago, Illinois.

660

Anderson, C. R. and F. G. Lindzey. 2003. Estimating cougar predation rates from GPS location

661 clusters. Journal of Wildlife Management 67:307-316.

662

Apps, C. D. and B. N. McLellan. 2006. Factors influencing the dispersion and fragmentation of

663 endangered mountain caribou populations. Biological Conservation 130:84-97.

664

Armstrong, D. P. and H. U. Wittmer. 2011. Incorporating Allee effects into reintroduction

665 strategies. Ecological Research 26:687-695.

666

Ballard, W. B., J. S. Whitman, and C. L. Gardner. 1987. Ecology of an exploited wolf population

667 in south-central Alaska. Wildlife Monographs 98:1-54.

668

Bergerud, A. T. and J. P. Elliot. 1986. Dynamics of caribou and wolves in northern British

669 Columbia. Canadian Journal of Zoology 64:1515-1529.

670

Bergerud, A. T. and J. P. Elliott. 1998. Wolf predation in a multiple-ungulate system in northern

671 British Columbia. Canadian Journal of Zoology 76:1551-1569.

672 Bird, C., R. Clarke, D. Lewis, and R. Serrouya. 2010. Cougar ecology, predation, and caribou in

673

674

675

676

677

678

679

680

681

682

683 the Columbia Mountains of British Columbia. Fish and Wildlife Compensation Program Columbia Basin, Nelson, British Columbia.

Boertje, R. D., M. A. Keech, and T. F. Paragi. 2010. Science and values influencing predator control for Alaska moose management. Journal of Wildlife Management 74:917-928.

Brockman, C. J., W. B. Collins, J. M. Welker, D. E. Spalinger, and B. W. Dale. 2017. Determining kill rates of ungulate calves by brown bears using neck-mounted cameras. Wildlife Society Bulletin 41:88-97.

Brown, T. L., D. J. Decker, S. J. Riley, J. W. Enck, T. B. Lauber, P. D. Curtis, and G. F. Mattfeld. 2000. The future of hunting as a mechanism to control white-tailed deer populations. Wildlife Society Bulletin 28:797-807. 
684 Burnham, K. P. and D. R. Anderson. 2002. Model selection and multimodel inference: a

685

686

687

688

689

690

691

692

693

694

695

696

697

698

699

700

701

702

703

704

705

706

707

708

709

710 practical information-theoretic approach. 2nd edition. Springer, New York.

Carpenter, S. R., S. W. Chisholm, C. J. Krebs, D. W. Schindler, and R. F. Wright. 1995. Ecosystem experiments. Science 269:324-327.

Caughley, G. 1977. Analysis of vertebrate populations. John Wiley \& Sons, New York, New York, USA.

Courchamp, F., R. Woodroffe, and G. Roemer. 2003. Removing protected populations to save endangered species. Science 302:1532.

Creel, S. and J. A. Winnie. 2005. Responses of elk herd size to fine-scale spatial and temporal variation in the risk of predation by wolves. Animal Behaviour 69:1181-1189.

Cubaynes, S., D. R. MacNulty, D. R. Stahler, K. A. Quimby, D. W. Smith, and T. Coulson. 2014. Density-dependent intraspecific aggression regulates survival in northern Yellowstone wolves (Canis lupus). Journal of Animal Ecology 83:1344-1356.

Dawe, K. L., E. M. Bayne, and S. Boutin. 2014. Influence of climate and human land use on the distribution of white-tailed deer (Odocoileus virginianus) in the western boreal forest. Canadian Journal of Zoology 92: 353-363.

DeCesare, N. J., M. Hebblewhite, M. Bradley, K. G. Smith, D. Hervieux, and L. Neufeld. 2012. Estimating ungulate recruitment and growth rates using age ratios. Journal of Wildlife Management 76:144-153.

Doak, D. F., J. A. Estes, B. S. Halpern, U. Jacob, D. R. Lindberg, J. Lovvorn, D. H. Monson, M. T. Tinker, T. M. Williams, J. T. Wootton, I. Carroll, M. Emmerson, F. Micheli, and M. Novak. 2008. Understanding and predicting ecological dynamics: are major surprises inevitable? Ecology 89:952-961.

Flaa, J.P. and B.N. McLellan. 2000. Population characteristics of the Lake Revelstoke caribou. Pages 639-642. In At Risk: Proceedings of a Conference on the Biology and Management of Species and Habitats at Risk. February 15-19, 1999, Kamloops, British Columbia. Ministry of Environment, Lands and Parks, Victoria, British Columbia, Canada. 
711 Fuller, T. K., L. D. Mech, and J. F. Cochrane. 2003. Wolf population dynamics. Pages 161-191 in

712 D. L. Mech and L. Boitani, editors. Wolves: behavior, ecology, and conservation. $713 \quad$ University of Chicago Press, Chicago.

714 Gaillard, J. M., M. Festa-Bianchet, and N. G. Yoccoz. 1998. Population dynamics of large 715 herbivores: variable recruitment with constant adult survival. Trends in Ecology \& $716 \quad$ Evolution 13:58-63.

717 Gasaway, W.C., S.D. DuBois, D.J. Reed, and S.J. Harbo. 1986. Estimating moose population 718 parameters from aerial surveys. Biological Papers No. 22, University of Alaska $719 \quad$ Fairbanks, Alaska, USA.

720 Gasaway, W. C., R. D. Boertje, D. V. Grangaard, D. G. Kelleyhouse, R. O. Stephenson, and D. G. 721 Larsen. 1992. The role of predation in limiting moose at low-densities in Alaska and 722 Yukon and implications for conservation. Wildlife Monographs 120:1-59.

723 Gasaway, W. C., R. O. Stephenson, J. L. Davis, P. E. K. Shepherd, and O. E. Burris. 1983. 724 Interrelationships of wolves, prey, and man in interior Alaska. Wildlife Monographs $725 \quad 84: 1-50$.

726 Gustine, D. D., K. L. Parker, R. J. Lay, M. P. Gillingham, and D. C. Heard. 2006. Calf survival of 727 woodland caribou in a multi-predator ecosystem. Wildlife Monographs 165:1-32.

728 Hayes, R. D., R. Farnell, R. M. P. Ward, J. Carey, M. Dehn, G. W. Kuzyk, A. M. Baer, C. L. Gardner, 729 and M. O'Donoghue. 2003. Experimental reduction of wolves in the Yukon: Ungulate 730 responses and management implications. Wildlife Monographs 152:1-35.

731

732

Heard, D.C. 2012. Presentation to the North American Caribou Conference, Sept 2012, Ft. St.

733

734 735 736 737 738 739 John, BC.

Hebblewhite, M. 2013. Consequences of ratio-dependent predation by wolves for elk population dynamics. Population Ecology 55:511-522.

Hebblewhite, M., C. White, and M. Musiani. 2010. Revisiting extinction in national parks: mountain caribou in Banff. Conservation Biology 24:341-344.

Hegel, T. M., A. Mysterud, F. Huettmann, and N. C. Stenseth. 2010. Interacting effect of wolves and climate on recruitment in a northern mountain caribou population. Oikos 119:14531461. 
740 Heisey, D. M. and T. K. Fuller. 1985. Evaluation of survival and cause-specific mortality rates 741 using telemetry data. Journal of Wildlife Management 49:668-674.

742 Heisey, D. M. and B. R. Patterson. 2006. A review of methods to estimate cause-specific 743 mortality in presence of competing risks. Journal of Wildlife Management 70:1544-1555.

744 Hervieux, D., M. Hebblewhite, D. Stepnisky, M. Bacon, and S. Boutin. 2014. Managing wolves 745 (Canis lupus) to recover threatened woodland caribou (Rangifer tarandus caribou) in $746 \quad$ Alberta. Canadian Journal of Zoology 92:1029-1037.

747 Hobson, K. A., B. N. McLellan, and J. G. Woods. 2000. Using stable carbon $(\delta 13 C)$ and nitrogen

748

749

750

751

752

753

754

755

756

757

758

759

760

761

762

763

764

765

766

767

768 $(\delta 15 N)$ isotopes to infer trophic relationships among black and grizzly bears in the upper Columbia River basin, British Columbia. Canadian Journal of Zoology 78:1332-1339.

Holt, R. D. 1977. Predation, apparent competition, and structure of prey communities. Theoretical Population Biology 12:197-229.

Kay, C. E. 1997. Aboriginal overkill and the biogeography of moose in western North America. Pages 141-164 in 32nd North American Moose Conference and Workshop, Banff, Canada.

Klafki, R., K.G. Poole, and R. Serrouya. 2009. Moose inventory of MU 3-40, Thompson Region, January-February 2009. BC Ministry of Forests and Range - Research Branch, Victoria $\mathrm{BC}$.

Knopff, K. H., A. A. Knopff, M. B. Warren, and M. S. Boyce. 2009. Evaluating global positioning system telemetry techniques for estimating cougar predation parameters. Journal of Wildlife Management 73:586-597.

Latham, A. D. M., M. C. Latham, N. A. McCutchen, and S. Boutin. 2011. Invading white-tailed deer change wolf-caribou dynamics in northeastern Alberta. Journal of Wildlife Management 75:204-212.

Lebel, F., C. Dussault, A. Masse, and S. D. Coté. 2012. Influence of habitat features and hunter behavior on white-tailed deer harvest. Journal of Wildlife Management 76:1431-1440.

Legebokow, C., and R. Serrouya. 2017. Population census of mountain caribou in the north Columbia Mountains - Columbia North subpopulation. British Columbia Ministry of Forests, Lands, and Natural Resource Operations. 
769 McDonald, J. E., D. E. Clark, and W. A. Woytek. 2007. Reduction and maintenance of a white$770 \quad$ tailed deer herd in central Massachusetts. Journal of Wildlife Management 71:1585$771 \quad 1593$.

772 McLellan, B. N. 2010. An historic perspective of mountain caribou distribution and abundance. 773 BC Ministry of Forests, Research Branch, Victoria, British Columbia.

774 McLellan, B. N. 2011. Implications of a high-energy and low-protein diet on the body 775 composition, fitness, and competitive abilities of black (Ursus americanus) and grizzly 776 (Ursus arctos) bears. Canadian Journal of Zoology 89:546-558.

777

778

779

780

781

782

783

784

785

786

787

788

789

790

791

792

793

794

795

796

797

McLellan, B.N. 2015. Some mechanisms underlying variation in vital rates of grizzly bears on a multiple use landscape. Journal of Wildlife Management. 79:749-765

McLellan, B.N., F. Hovey, J. Woods, M. Gibeau, D. Carney, R. Mace, W. Wakkinen, W. Kasworm. 1999. Rates and causes of grizzly bear mortality in the interior mountains of British Columbia, Alberta, Montana, and Idaho. Journal of Wildlife Management 63:911-920.

McLellan, B. N., R. Serrouya, J. Flaa. 2006. Population censuses of caribou in the north Columbia Mountains. Unpublished report for the BC Ministry of Forests, Research Branch.

McLellan, B. N., R. Serrouya, H. U. Wittmer, and S. Boutin. 2010. Predator-mediated Allee effects in multi-prey systems. Ecology 91:286-292.

McLoughlin, P. D., E. Dzus, B. Wynes, and S. Boutin. 2003. Declines in populations of woodland caribou. Journal of Wildlife Management 67:755-761.

Mech, L. D. 1977. Productivity, mortality, and population trends of wolves in northeastern Minnesota. Journal of Mammalogy 58:559-574.

Messier, F. 1985. Social organization, spatial distribution, and population density of wolves in relation to moose density. Canadian Journal of Zoology 63:1068-1077.

Messier, F. 1994. Ungulate population models with predation: a case study with the North American moose. Ecology 75:478-488.

Mills, K. J., B. R. Patterson, and D. L. Murray. 2008. Direct estimation of early survival and movements in eastern wolf pups. Journal of Wildlife Management 72:949-954.

Mosnier, A., D. Boisjoly, R. Courtois, and J. P. Ouellet. 2008. Extensive predator space use can limit the efficacy of a control program. Journal of Wildlife Management 72:483-491. 
798 Mowat, G., D. C. Heard, and C. J. Schwarz. 2013. Predicting grizzly bear density in western North $799 \quad$ America. PLoS ONE 8(12): e82757. doi:10.1371/journal.pone.0082757

800 Murray, D. L. 2006. On improving telemetry-based survival estimation. Journal of Wildlife $801 \quad$ Management 70:1530-1543.

802 Orians, G., P. A. Cochran, J. W. Duffield, T. K. Fuller, R. J. Gutierrez, W. M. Henemann, F. C. 803 James, P. Kereiva, S. R. Kellert, D. Klein, B. N. McLellan, P. D. Olson, and G. Yaska. 1997. 804 Wolves, bears, and their prey in Alaska. National Academy Press, Washington.

805 Peterson, R. O., N. J. Thomas, J. M. Thurber, J. A. Vucetich, and T. A. Waite. 1998. Population 806 limitation and the wolves of Isle Royale. Journal of Mammalogy 79:828-841.

807 Peterson, R. O., J. D. Woolington, and T. N. Bailey. 1984. Wolves of the Kenai Peninsula, Alaska. $808 \quad$ Wildlife Monographs 88:3-52.

809 Polfus, J. L. and P. R. Krausman. 2012. Impacts of residential development on ungulates in the $810 \quad$ Rocky Mountain west. Wildlife Society Bulletin 36:647-657.

811 Post, E. and N. C. Stenseth. 1998. Large-scale climatic fluctuation and population dynamics of 812 moose and white-tailed deer. Journal of Animal Ecology 67:537-543.

813 Rettie, W. J. and F. Messier. 1998. Dynamics of woodland caribou populations at the southern 814 limit of their range in Saskatchewan. Canadian Journal of Zoology 76:251-259.

815

816

817

818

819

820

821

822

823

824

825

Ricciardi, A., R. J. Neves, and J. B. Rasmussen. 1998. Impending extinctions of North American freshwater mussels (Unionoida) following the zebra mussel (Dreissena polymorpha) invasion. Journal of Animal Ecology 67:613-619.

Santomauro, D., C. J. Johnson, and G. Fondahl. 2012. Historical-ecological evaluation of the long-term distribution of woodland caribou and moose in central British Columbia. Ecosphere 3:37.

Seip, D. R. 1992. Factors limiting woodland caribou populations and their interrelationships with wolves and moose in southeastern British Columbia. Canadian Journal of Zoology 70:1494-1503.

Seip, D. R. 2008. Mountain caribou interactions with wolves and moose in central British Columbia. Alces 44:1-5. 
826 Serrouya, R. 2013. An adaptive approach to endangered species recovery based on a

827 management experiment: reducing moose to reduce apparent competition with

828 woodland caribou. University of Alberta, Edmonton.

829 Serrouya, R., S. Gilbert, R. S. McNay, B. N. McLellan, D. C. Heard, D. R. Seip, and S. Boutin. 2017. 830 Comparing population growth rates between census and recruitment-mortality models. 831 Journal of Wildlife Management 81:297-305.

832 Serrouya, R., B. N. McLellan, and S. Boutin. 2015b. Testing predator-prey theory using 833 broad-scale manipulations and independent validation. Journal of Animal Ecology $834 \quad 84: 1600-1609$.

835 Serrouya, R., B. N. McLellan, S. Boutin, D. R. Seip, and S. E. Nielsen. 2011. Developing a 836 population target for an overabundant ungulate for ecosystem restoration. Journal of 837 Applied Ecology 48:935-942.

838 Serrouya, R., D. Paetkau, B. N. McLellan, S. Boutin, M. Campbell, and D. A. Jenkins. 2012. 839 Population size and major valleys explain microsatellite variation better than taxonomic $840 \quad$ units for caribou in western Canada. Molecular Ecology. 21:2588-2601.

841 Serrouya, R., M. J. Wittmann, B. N. McLellan, H. U. Wittmer, and S. Boutin. 2015a. Using 842 predator-prey theory to predict outcomes of broadscale experiments to reduce apparent competition. The American Naturalist 185:665-679.

Serrouya, R. and H. U. Wittmer. 2010. Imminent extinctions of woodland caribou from national 845 parks. Conservation Biology 24:363-364.

Simard, M. A., C. Dussault, J. Huot, and S. D. Côté. 2013. Is hunting an effective tool to control overabundant deer? A test using an experimental approach. Journal of Wildlife Management 77:254-269.

849

Sinclair, A. R. E. 1995. Population limitation of resident herbivores. Pages 194-219 in A. R. E.

850 Sinclair and P. Arcese, editors. Serengeti II: Dynamics, management, and conservation of an Ecosystem. The University of Chicago Press, London.

852 Sinclair, A. R. E., R. P. Pech, C. R. Dickman, D. Hik, P. Mahon, and A. E. Newsome. 1998. Predicting effects of predation on conservation of endangered prey. Conservation Biology 12:564-575. 
855 Smith, A. P. and D. G. Quin. 1996. Patterns and causes of extinction and decline in Australian $856 \quad$ conilurine rodents. Biological Conservation 77:243-267.

857 Spalding, D. J. 1990. The early history of moose (Alces alces): distribution and relative 858 abundance in British Columbia. Contributions of Natural Science No. 11. Royal 859 B.C.Museum, Victoria, British Columbia.

860 Spalding, D.J. 2000. The early history of woodland caribou (Rangifer tarandus caribou) in British 861 Columbia. Wildlife Bulletin No. B-100. Ministry of Environment, Lands and Parks, $862 \quad$ Victoria, British Columbia.

863 Sparkman, A. M., L. P. Waits, and D. L. Murray. 2011. Social and demographic effects of 864 anthropogenic mortality: A test of the compensatory mortality hypothesis in the red 865 wolf. PloS ONE 6 e20868. https://doi.org/10.1371/journal.pone.0020868

866 Steenweg, R. 2011. Interactions of wolves, mountain caribou, and an increased moose-hunting 867 868 quota - primary-prey management as an approach to caribou recovery. M.Sc. Thesis, University of Northern British Columbia, Prince George, British Columbia.

Stotyn, S. 2008. Ecological interactions of mountain caribou, wolves and moose in the north

870

871

van Oort, H., B. N. McLellan, and R. Serrouya. 2011. Fragmentation, dispersal and

872

873 metapopulation function in remnant populations of endangered mountain caribou.

874 Animal Conservation 14:215-224.

875

Vucetich, J. A., M. Hebblewhite, D. W. Smith, and R. O. Peterson. 2011. Predicting prey

876 population dynamics from kill rate, predation rate and predator-prey ratios in three wolf-ungulate systems. Journal of Animal Ecology 80:1236-1245.

877 Webb, N. F., J. R. Allen, and E. H. Merrill. 2011. Demography of a harvested population of 878 879 wolves (Canis lupus) in west-central Alberta, Canada. Canadian Journal of Zoology 89:744-752.

880 Wittmer, H. U., R. N. M. Ahrens, and B. N. McLellan. 2010. Viability of mountain caribou in 881 British Columbia, Canada: effects of habitat change and population density. Biological Conservation 143:86-93. 
883 Wittmer, H. U., L. M. Elbroch, and A. J. Marshall. 2013a. Good intentions gone wrong: did 884 conservation management threaten Endangered huemul deer Hippocamelus bisulcus in 885 the future Patagonia National Park? Oryx 47:393-402.

886 Wittmer, H. U., B. N. McLellan, D. R. Seip, J. A. Young, T. A. Kinley, G. S. Watts, and D. Hamilton. 887 2005a. Population dynamics of the endangered mountain ecotype of woodland caribou 888 (Rangifer tarandus caribou) in British Columbia, Canada. Canadian Journal of Zoology $889 \quad 83: 407-418$.

890 Wittmer, H. U., R. Serrouya, L. M. Elbroch, and A. J. Marshall. 2013b. Conservation strategies for 891 species affected by apparent competition. Conservation Biology 27: 254-260.

892 Wittmer, H. U., A. R. E. Sinclair, and B. N. McLellan. 2005b. The role of predation in the decline 893 and extirpation of woodland caribou. Oecologia 144:257-267.

894 
895

896

\section{APPENDIX 1. MOOSE POPULATION TREND COMPARISON BETWEEN THE TREATMENT AND REFERENCE}

AREAS.

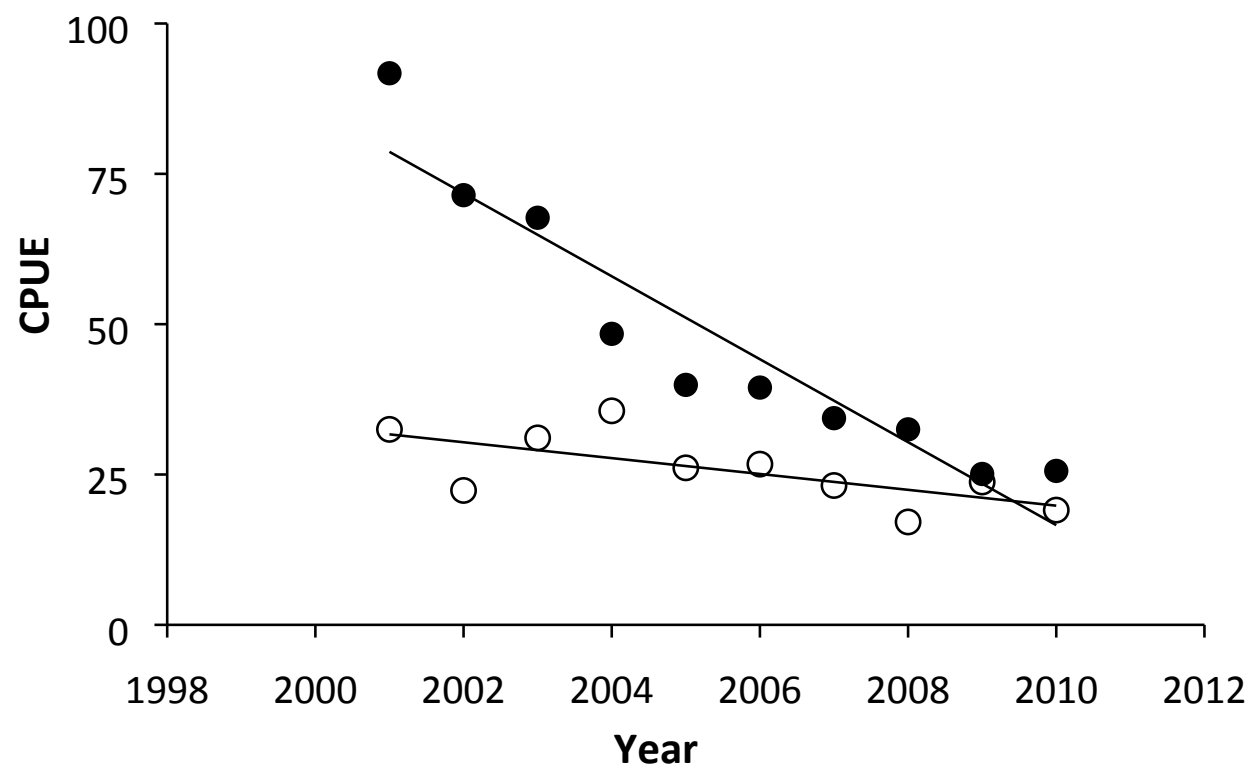

897

898 Figure Al: The slope of decline was more than five times greater in the treatment (solid circles)

899 compared to the reference area (open circles; slopes were -6.88 [ -9.02 to -4.68$]$ compared to $900-1.32$ [ -2.46 to -0.26 ] for the respective treatment and reference areas; 1000 bootstrapped

901 iterations). The slopes estimated here are slightly different from Serrouya et al. (2015b)

902 because the reference area was larger to accommodate the wolf ranges and caribou

903 subpopulations. Nonetheless, the ratio of the slopes between the two areas (i.e. comparing the 904 magnitude of change between the treatment and reference) was similar when the smaller or 905 larger reference area was compared to the treatment area.

906

907

908 